\title{
DIE INVLOED VAN VERSKEIE VERPLEEGKUNDIGE PROSEDURES EN RUS OP DIE INTRAKRANIALE DRUK VAN DIE HOOFBESEERDE PASIENT
}

\author{
Margot J Hugo
}

\begin{abstract}
Psomming
Die toenemende invalsyfer van hoofbeserings na motorvoertuigongelukke het die navorsing genoodsaak. Ondersoek is ingestel om die invloed van verpleegsorg en geskectuleerde rusperiodes op die intrakaniale druk van die hoofbeseerde pasiènt te bestudeer. 'n Eksperimentele ontwerp is gebruik in die empiriese sudie waartydens 23 pasiēnte observeer is. Hocwel daar nie 'n betekenisvolle verskil ussen die eksperimentele en kontrole groep aangedui kon word Lo.v. die invloed van rusperiodes op IKD nie, word die effek van die verskillende verpleegsorghandelinge duidelik weerspiëel. Deeglike beplanning van verpleegsorg is derhalwe 'n belangrike faktor wat altyd in gedagte gehou moet word.

\section{Summary}

The increasing number of head injuries following motor vehicle accidents have made this research important. The effect of nursing care activities and scheduled rest periods on the intracranial pressure of the head injured parient was studied An experimental design was used in the empirical study where 23 patients were observed. Although a significant difference could not be demonstrated between the experimental and control groups in terms of the influence of rest periods the effect of the various rsing care procedures is clearly demonstrated, and careful planning of nursing care is therefore an important factor that must always be borne in mind.
\end{abstract}

\section{INLEIDING}

Die toenemende invalsyfer van hoofbeseerdes in trouma-insidente en dic hoè voorkoms daarvan in die ouderdomsgroep 15 tot 30 jaar noodsaak die bcstudering van die verpleegsorg van hierdie pasiente. Die invloed van verpleegsorg moet bestudeer en ontleed word, sodat sinvolle en wctenskaplike verpleegsorgbeplanning aan dic hand van die resultate kan geskied.

Mitchell (1980:150) het kumulaticwe drukstygings waargeneem wanneer prosedures 15 minute uitmekaar voorgekom het. Bruya (1981:184-194) het 'n soortgelyke studie gedoen waartydens sy 10 minute rusperiodes voor elke prosedure toegelaat het. Wcer eens was die bevinding dat ' $n$ algehele rusperiode van 10 minute nie enige verskil gemaak het nie en drukke steeds kumulatief gestyg het. Mitchell, Ozuna \& Lipe het egter bevind dat waar die pasiënt ten minste een uur kon rus, daar wel 'n betekenisvolle verskil was, aangesien druk voldoende tyd gehad het om na die basislyn tcrug te keer $(1981: 217)$. Hoewel dit dikwels moeilik is om 'n pasiënt in 'n kritieke sorgeenheid vir 'n uur te laat rus, beklemtoon dit $\operatorname{tog}$ die feit dat noukeurige verplecgsorgbeplanning kan bydra tot beter beheer van intrakraniale druk (Mitchell 1980:153).

Shalit \& Umansky (1977:886) gaan selfs so ver deur tc beweer "that the cumulative effect of increases in intracranial pressure which take place during routine management of these patients may be a major factor in determining the outcome of the illness".

Aangesien verhoogde intrakraniale druk (IKD) as komplikasie van ernstige hoofbeserings algemeen voorkom en dié druk kwalitatief en kwantitatief meetbaar is, is dit as parameter in die studie gebruik. Die navorsing is gedoen by 'n eenheid met die grootste populasie pasiente wie se IKD gemonitor word, en wat vir die navorser toeganklik was.

\section{METODOLOGIE}

'n Eksperimentele navorsingsontwerp is in die empiriese studie gebruik. Die volgende insluitingskriteria het gegeld vir alle pasiënte wat as gevolg van 'n ernstige hoofbesering in die geselekteerde neurochirurgiese eenheid opgencem is:

- 'n Komaskaaltelling van 8 of minder met opname,

* 'n abnormale rekenaartomografiese skandering,

* 'n progressiewe toestand,

* druk wat nie vir minder as 12 ure gemonitor is nie, en

* intrakraniale druk wat met 'n epidurale sensor gemonitor word.

Ontledingseenheid: 'n Ewekansige groepontwerp is gebruik. Die pasiënte is op alternatiewe wyse in 'n eksperimentele en kontrole groep verdeel. Gedurende die ses maande wat die veldwerk geduur het is 23 pasiènte wat aan die ins/uitingskriteria voldoen het in die eenheid opgeneem. Daar was elf in die eksperimentele en twaalf in die kontrole groep.

Manipulasie van die veranderlikes en opnames: Verpleegsorg is oor 'n tydperk van 72 uur as volg gemanipuleer en die onderstaande opnames gedoen: die kontrole groep het roetine versorging volgens die eenheidsprotokol ontvang, terwyl die eksperimentele groep 'n dertig minute rusperiode gehad het, waartydens die pasiènt glad nie gesteur is voordat roetine versorging ' $n$ aanvang geneem is nie. Tydens hul versorging, is daar ook doelbewus met die eksperimentele groep gekommunikeer.

Die volgende opnames is gedoen:

- Die gemene IKD is gemonitor. 
- Die basislyndruk is voor aanvang van 'n prosedure bepaal.

- Die maksimum (of piekdruk) gedurende die prosedure is bepaal.

- Die tydsduur vandat styging 'n aanvang geneem het totdat dit na die basislyndruk teruggekeer het.

- Die posisie waarin die pasiënt tydens die uitvoer van 'n prosedure verkeer het.

- Die tipe medikament wat die pasiënt vir die beheer van IKD ontvang het.

Dic waarnemings is vir 'n tydperk van 72 uur volgehou, tensy die pasiënt se drukmeting vroeër getermineer is, maar in geen geval was dit korter as 12 ure nie. Die waamemings was gedurende bedwas, herposisionering, brongiale toilet, mondtoilet, pupilreaksies, hoes, pyn, bibbering en kommunikasie uitgevoer. Die waarnemings is slegs onderbreek wanneer daar 'n krisis ontstaan het wat die pasiënt se lewe kon bedreig.

As 'n nie-deelnemende waarnemer het die navorser al die waarnemings en monitering van die pasiënte vir die volle duur van die navorsing self uitgevœer. Hierdeur kon die navorser die IKD-veranderinge na elkeen van die veranderlikes monitor en noteer. Die navorser het op geen wyse enige gebeurtenis gemanipuleer nie. Die personeel het egter matreëls soos gekontroleerde hiperventilasie tocgepas om die duur van drukstyging te verkort.

\section{ONTLEDING VAN DATA EN BEVINDINGE}

Die invloed van die onderskeie onafhanklike veranderlikes op die IKD word in tabel 1 uiteengesit en die metings van die eksperimentele en kontrole groep word vergelyk. Geen statisties betekenisvolle verskil kon tussen die groepe aangedui word nie. Moontlike verklarings vir hierdie verskynsel mag wees dat die eksperimentele groep 'n hoër morbiditeit, terwyl die kontrole groep 'n hoèr mortaliteit gehad het. Daar was ook meer pasiënte in die kontrole groep wat barbituraatterapie ontvang het en gevolglik minder IKD-veranderinge getoon het. Die eksperimentele groep het ook 'n hoër breinelastans as die kontrole groep gehad. Wanneer die brein swel en min meegewendheid oorbly, word daarna verwys as 'n hoë breinclastans (brain elastance). Daar is gevolglik 'n gebrek aan meegewenheid of elastisiteit.

'n Verdere moontlike verklaring vir die feit dat die eksperimentele en kontrole groepe nie veel verskil het nie, mag wees dat die kontrole groep dikwels ook tien tot vyftien minute gerus het voordat verpleegsorghandelinge toegepas is, aangesien dit deel vorm van die bestaande saalprotokol. Hierdie bevindinge stem ooreen met đié van Bruya (1981:184-194), wat 'n tien-minute rusperiode toegelaat het. Mitchell et al (1981:217) rapporteer egter 'n statisties betekenisvolle drukverskil wanneer 'n rusperiode van een uur toegelaat word. Hoewel dus nie altyd prakties moontlik nie, wil dit tog lyk asof rus wel 'n belangrike rol speel, maar dat
Tabel 1

Gemiddelde intrakranlale drukstygings van proefpersone In verhouding tot die onafhanklike veranderlikes

\begin{tabular}{|c|c|c|c|c|c|}
\hline $\begin{array}{l}\text { ONAFHANKLIKE } \\
\text { VERANDERLIKES }\end{array}$ & $\begin{array}{l}\text { PROEF- } \\
\text { PERSONE }\end{array}$ & $\begin{array}{l}\text { X-BASIS } \\
\text { DRUK }\end{array}$ & $\begin{array}{l}\text { X-DRUK } \\
\text { STYGING }\end{array}$ & $\begin{array}{l}\text { MINIMUM } \\
\text { STYGING }\end{array}$ & $\begin{array}{l}\text { MAKSF } \\
\text { MUM } \\
\text { STYGING }\end{array}$ \\
\hline $\begin{array}{l}\text { 1. Bedwas } \\
\text { ne } \\
n k \\
n\end{array}$ & $\begin{array}{l}11 \\
12 \\
23\end{array}$ & $\begin{array}{l}10,29 \\
13,05 \\
11,73\end{array}$ & $\begin{array}{l}10,73 \\
10,32 \\
10,51\end{array}$ & $\begin{array}{l}5,31 \\
3,92 \\
3,92\end{array}$ & $\begin{array}{l}19,50 \\
18,88 \\
19,50\end{array}$ \\
\hline $\begin{array}{l}\text { 2. Herposisionering } \\
\text { ne } \\
\text { nk } \\
n\end{array}$ & $\begin{array}{l}11 \\
12 \\
23\end{array}$ & $\begin{array}{l}10,97 \\
15,78 \\
13,48\end{array}$ & $\begin{array}{l}17,37 \\
14,17 \\
15,70\end{array}$ & $\begin{array}{l}6,17 \\
2,00 \\
2,00\end{array}$ & $\begin{array}{l}39,18 \\
24,42 \\
39,18\end{array}$ \\
\hline $\begin{array}{l}\text { 3. Brongiale toilet } \\
\text { ne } \\
n k \\
n\end{array}$ & $\begin{array}{l}11 \\
12 \\
23\end{array}$ & $\begin{array}{l}10,30 \\
12,35 \\
11,37\end{array}$ & $\begin{array}{l}28,79 \\
25,51 \\
27,07\end{array}$ & $\begin{array}{l}17,65 \\
9,57 \\
9,57\end{array}$ & $\begin{array}{l}41,00 \\
37,55 \\
41,00\end{array}$ \\
\hline $\begin{array}{l}\text { 4. Mondtoilet } \\
n \theta \\
n k \\
n\end{array}$ & $\begin{array}{l}11 \\
12 \\
23\end{array}$ & $\begin{array}{l}10,59 \\
13,33 \\
11,96\end{array}$ & $\begin{array}{c}12,02 \\
8,97 \\
10,49\end{array}$ & $\begin{array}{l}4,14 \\
3,00 \\
3,00\end{array}$ & $\begin{array}{l}25,17 \\
24,67 \\
25,17\end{array}$ \\
\hline $\begin{array}{l}\text { 5. Pupilreaksies } \\
\text { ne } \\
\text { nk } \\
n\end{array}$ & $\begin{array}{l}11 \\
12 \\
23\end{array}$ & $\begin{array}{l}10,67 \\
13,52 \\
12,16\end{array}$ & $\begin{array}{l}2,02 \\
2,06 \\
2,04\end{array}$ & $\begin{array}{l}-1,55 \\
0,25 \\
-1,55\end{array}$ & $\begin{array}{l}3,36 \\
3,80 \\
3,80\end{array}$ \\
\hline $\begin{array}{l}\text { 6. Hoes } \\
\text { ne } \\
n k \\
n\end{array}$ & $\begin{array}{l}11 \\
12 \\
23\end{array}$ & $\begin{array}{l}12,27 \\
3,85 \\
9,68\end{array}$ & $\begin{array}{l}37,07 \\
26,38 \\
33,26\end{array}$ & $\begin{array}{l}19,00 \\
17,00 \\
17,00\end{array}$ & $\begin{array}{l}81,00 \\
31,71 \\
81,00\end{array}$ \\
\hline $\begin{array}{l}\text { 7. Pyn } \\
\text { ne } \\
\text { nk } \\
n\end{array}$ & $\begin{array}{l}11 \\
12 \\
23\end{array}$ & $\begin{array}{l}9,96 \\
8,56 \\
9,31\end{array}$ & $\begin{array}{l}15,15 \\
13,04 \\
14,16\end{array}$ & $\begin{array}{l}5,50 \\
4,60 \\
4,60\end{array}$ & $\begin{array}{l}28,50 \\
21,00 \\
28,50\end{array}$ \\
\hline $\begin{array}{l}\text { 8. Bibbering } \\
\text { ne } \\
n k \\
n\end{array}$ & $\begin{array}{l}11 \\
12 \\
23\end{array}$ & $\begin{array}{c}13,10 \\
7,00 \\
11,36\end{array}$ & $\begin{array}{l}13,90 \\
15,50 \\
14,36\end{array}$ & $\begin{array}{l}7,00 \\
9,00 \\
7,00\end{array}$ & $\begin{array}{l}35,50 \\
22,00 \\
35,50\end{array}$ \\
\hline $\begin{array}{l}\text { 9. Kommunikasie } \\
\text { ne } \\
n k \\
n\end{array}$ & $\begin{array}{l}11 \\
12 \\
23\end{array}$ & $\begin{array}{l}13,39 \\
17,40 \\
15,40\end{array}$ & $\begin{array}{l}1,24 \\
1,17 \\
1,21\end{array}$ & $\begin{array}{l}-4,25 \\
-2,71 \\
-4,25\end{array}$ & $\begin{array}{c}13,00 \\
7,00 \\
13,00\end{array}$ \\
\hline
\end{tabular}

$\mathbf{n}=$ totale deelnemende populasie

ne = eksperimentele groep

$n k=$ kontrole groep

die kwaliteit van rus moontlik die oorwegende faktor behoort te wees.

Uit die beskikbare inligting blyk dit nou dat globaal gesien daar moontlik tog 'n verklaring vir die verskynsel in tabel 1 is. Die hipotese dat rus 'n positiewe invloed op verhoogde IKD het, kan dus nie summier verwerp word nie, al kon daar nie 'n betekenisvolle verskil aangedui word nie.

Die belangrike aspek wat na vore kom en wat 'n rol mag speel by verpleegsorgbeplanning, is die invloed van die verskillende verpleegsorghandeling op die IKD. Die gemiddelde basislyndruk voor herposisionering was byvoorbeeld 13,48 $\mathrm{mmHg}$. Met piekstygings van tot soveel as $39,18 \mathrm{mmHg}$, bring dit die gemiddelde piekdruk by $\mathbf{5 2 , 6 6}$ $\mathrm{mmHg}$ en die piekdruk tydens brongiale toilet by $52,73 \mathrm{mmHg}$, wat 'n gevaarlike hoë breinelastans is. (Kyk figuur 1).

\section{AANBEVELINGS EN SLOT}

Die skedulering van verpleegsorghandelinge vorm die basis van die beplanning van verpleegsorg. Indien 'n pasiënt 'n hoe breinelestans het en hy geneig is tot baie pieken platodrukstygings, moet onnodige verpleegoptredes met langer tussenposes geskeduleer word. Bedwas kan byvoorbeeld elke ses tot agt ure of selfs elke twaalf ure geskeduleer word, mits die pasiënt nie as gevol $g$ van die ontstaan van dekubitus ulsera of ander komplikasies benadeel sal word nie. Onnodige aggitasic van die pasiënt moet te alle tye vermy word, maar die pasiènt moet egter nie aan sensoriese deprivasie blootgestel word nie.

Verpleegsorghandelinge wat 'n negatiewe invloed op die intrakraniale druk uitoefen moet nie saamgevoeg of opeenvolgend uitgevoer word nie. Aangesien bedwas, 


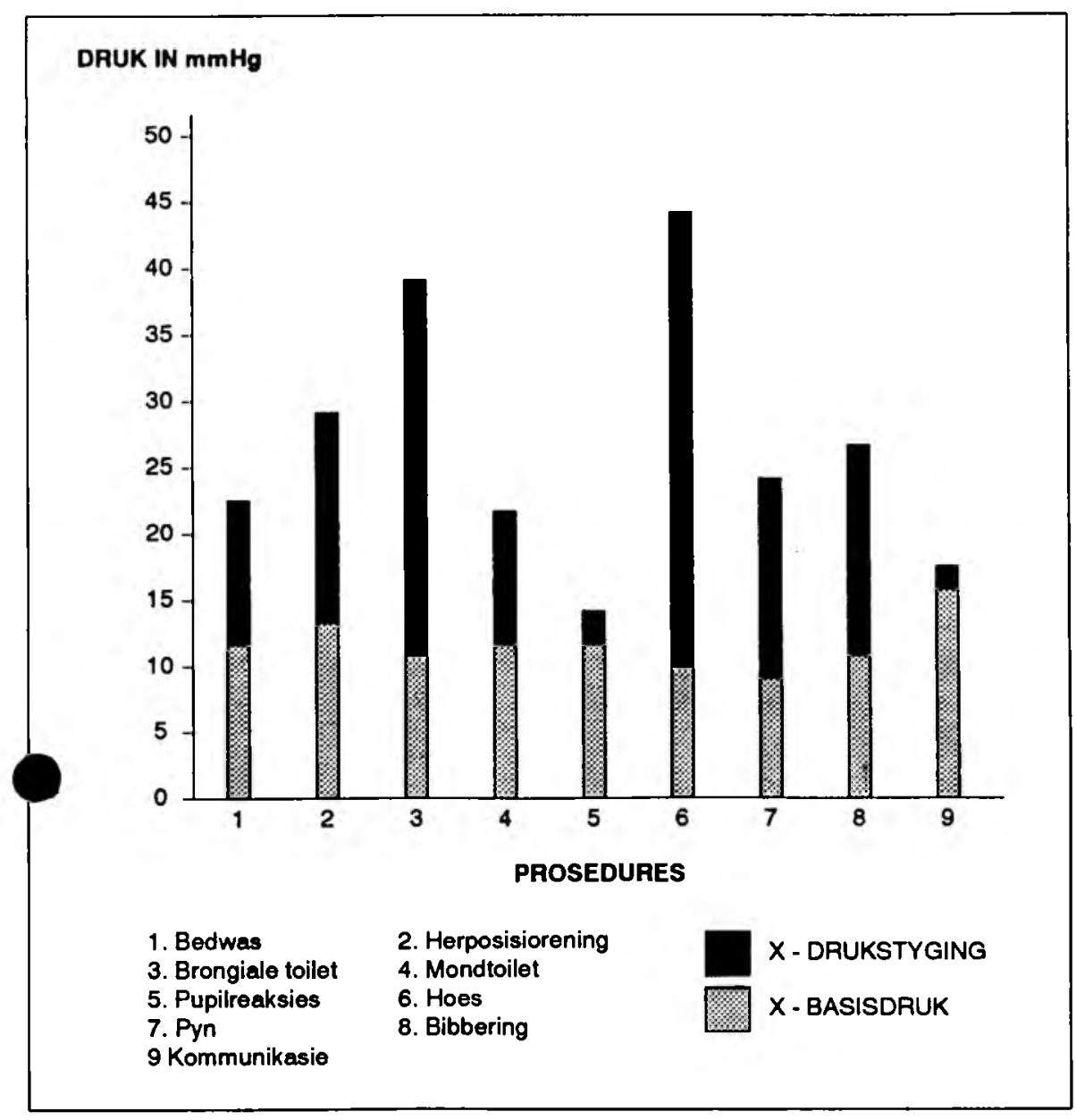

\section{Gemiddelde IKD - stygings van totale deelnemende populasie per onafhanklike veranderlike}

herposisionering, brongiale toilet en mondtoilet die pasiënt se IKD soms betekenisvol laat styg, moet hierdie prosedures noukeurig geskeduleer word en nie almal opeenvolgend uitgevoer word nie, aangesien dit 'n kumulatiewe effek sal hè.

doende rusperiodes moet ook geskeduleer

d. Dit sou blyk dat die kwaliteit eerder as die kwantiteit van die rusperiodes die betekenisvolle verskil maak. Dit is gevolglik essensieël dat alle aktiwiteite in ag geneem sal word, byvoorbeeld doktersrondte, arbeids- en fisioterapie, diagnostiese prosedures,
Die belangrikste aspek, en dit kan nie genoeg bcklemtoon word nie, is dat die skedulering van pasiëntsorg deur die pasiènt bepaal word en nie deur die verpleegkundige nie.

\section{GERAADPLEEGDE WERKE}

BRUYA, MA. Planned periods of rest in the intensive care unit: Nursing care activities and intracranial pressure. Journal of Neurosurgical Nursing, 13(4), 1981:184-194.

MITCHELL, PH. Intracranial hypertension: Implications of research for nursing care. Journal of Neurosurgical Nursing, 12(3), 1980:145-154.

MITCHELL, PH, OZUNA, J AND LIPE, HP. Moving the patient in bed: Effects on intracranial pressure. Nursing Research, $30(4), 1981: 212-218$

SHALIT, MN AND UMANSKY, F. The effect of routine bedside procedures on intracranial pressure. Israel Journal of Medical Science, 13,1977:881-886.

Hierdie artikel is'n uittreksel uit 'n doktorale tesis wat in 1989 voltooi is. verpleegsorghandelinge en besoeke deur gesinslede. Waar dit essensieël is dat bepaalde prosedures uitgevoer word, moet 'n basislyndruk van minder as $15 \mathrm{mmHg}$ verseker word voordat die bepaalde prosedures uitgevoer word. Medikamente wat die pasiënt minder sensitief maak vir die prosedure kan togedien word. Die invloed van die prosedure op die IKD van die pasient kan verder beperk word deur voortdurend op ' $\mathrm{n} \mathrm{kalm}$ en rustige wyse met die pasiënt te kommunikcer en die prosedure so vinnig moontlik met so min moontlik stimulasie af te handel.
Margol J Hugo

D SOC SC (Verpleegkunde)

Universitcit van die Oranje-Vrystaat 